\title{
FOOD POLICY COUNCIL AS CIVIC ENGAGEMENT FOR FOOD ISSUES
}

\begin{abstract}
Masashi Tachikawa
College of Agriculture, Ibaraki University, Ami-town, Ibaraki Prefecture 300-0393, Japan

E-mail: masashi.tachikawa.3@vc.ibaraki.ac.jp

Citation: Tachikawa, M., 2017. Food Policy Council as Civic Engagement for Food Issues. J. Asian Rur. Stud. 1(1): 19-27

Abstract: The purpose of this paper is to elucidate the nature of food issue in our society and propose a forum to discuss multi-facet issues of food based on the North American experience, such as food policy council (FPC). Contemporary food system in Japan is full of problems, such as low level self-sufficiency, food loss, problem of food access, large food miles, declining food culture under globalization, and so on. After reviewing these food related issues, the paper refers to the US and Canadian experiences on food policy council as a model to provide a forum for various stakeholders with different or even conflicting interests. Based on observations on the FPCs, such as Knoxville (US) and Toronto (Canada), author emphasized public aspect of food issues and draw attentions to differences in structural aspects of food between North America and Japan. The paper also tries to draw attention to differences between North America and Japan in terms of food issues. In particular, the demographic and geographical differences would exist of a major structural aspect when considering food issue in Japan.
\end{abstract}

Keywords: Food policy council; Civic engagement; Food issues

\section{Introduction}

Contemporary food system in Japan is full of problems, such as low level self-sufficiency, food loss, problem of food access, large food miles, declining food culture under globalization, and so on. Japanese food self-sufficiency rate has fallen to the level of about 40\% (in terms of calorie) for last decade (MAFF, 2016a). This is because the size of Japanese agricultural production declines and domestic meat industry heavily depends on imported feed. While Japanese food shows high level of dependency on foreign grain, a large amount of food loss is generated daily through 
various occasions in Japan (Kobayashi, 2015). At the same time, Japanese people are also facing difficulty with access to food. This totally paradoxical situation is happening today. In this paper, I will overview the current situation of Japanese food system and draw some implications for the future agenda for Japanese food system. One of the implications drawn from North American experiences on food issues is provisional possibility to form food policy councils in Japan.

\section{Discussion}

\subsection{Current Food Issues in Japan}

\subsubsection{Food Loss}

According to statistical data of the Japanese Ministry of Agriculture, Forestry and Fisheries (MAFF, 2016b), about 7.6\% (6.32 million ton) of food (edible part) is discarded without being consumed in 2013. The amount of food loss is nearly twice of total amount of food aid provided globally (3.2 million ton). Source of food loss can be classified as either household or industry, and they are equally responsible for food loss. Discarded food is partly utilized as animal feed and fertilizer (MAFF, 2016b). But it is really a large waste for Japanese society which is highly dependent on imported food.

Food loss is created by many factors, such as oversupply of food at retailers to avoid "opportunity loss," setting shorter period for "best consumed" labeling to avoid food safety risk, and food culture to provide abundant food to guests (Kobayashi, 2015). Also, there are some other sources which routinely cause large amount of food waste, such as Japanese retailers' custom to set time limit for sale and customary overprovision of food for social ceremony, such as wedding table. In Japan, "1/3 rule" tend to be regarded as major source of food waste in retail sector (MAFF, 2016b). Under this customary rule, retailers do not sell food items on their shelves once the remaining period of processed food decrease less than $1 / 3$ until the date designated as "best consumed." At the same time, more than 20 percent of food items are wasted for food served at wedding ceremony (MAFF, 2006). Other issues such as agricultural standards set for fresh produce constitute as sources to create food waste at farmers' field level. In case of highly processed food, food banks are making effort to distribute those foods to various households in need. Against this backdrop, the MAFF has initiated "No-Food Loss Project" from 2013 with various stakeholders, such as retailers, food manufacturers and so on (MAFF, 2016b). 


\subsubsection{Food Access}

On the other side of waste, many people, aged people in particular, are feeling difficulty in food access. Definition of food desert is varied depending on researchers, but the typical one is as follows: district or area where residents have difficulty to purchase fresh produce (Yakushiji, 2015). In particular, this type of district is characterized with residents with fewer opportunities of transportation.

There are many programs which are addressing the issue of food desert in urban area. For example, the Ministry of Economy, Trade and Industry (METI) has initiated a program to support urban residents who have difficulty in food access by providing additional transportation and web-based shopping (METI, 2015). It would be safe to mention that major counter measures to solve food access problem can be categorized into two types; either helping people to move or helping retailers to distribute goods. These measures tend to take status quo of existing commercial activities intact. Food access issue in Japan is being exacerbated as population of aged people increase in urban district where small retailers terminate their business because large shopping malls open in adjacent location. Difficulty to purchase fresh produce might cause health problem among aged people. Also, fewer opportunity to go out cause less personal contact with others, and weaken mutual ties within community. This situation calls for close coordination with welfare and health care division of local government and support elderly people from various aspects of their life beyond just to help shopping, such as medical check, emergency call, and so on.

\subsubsection{Food Safety}

Food safety issues have been attracting a wide attention from consumers. This is true for all over the world after the series of food safety incidents, such as pesticide residue, BSE, O157, GMOs, and so on. In the recent context of Japan, after the disaster of the Greater Earthquake in North-East Japan and following accident of the Fukushima Daiichi Nuclear Power Plant, Japanese consumers' concern over food had skyrocketed. Government's provisional measures to decrease radioactive material had even exacerbated consumers' trust on their food, and allow private companies to introduce more stringent counter measures. For example, the Aeon supermarket group in Japan had declared that they would achieve zero level of radioactive materials at their market shelf. From scientists' viewpoint, achieving zero level of radioactive materials is impossible, since even natural potassium $(\mathrm{K})$ contains radioactive which is widely observable in food (Uneyama, 2011). Here the discourse of zero-risk is manufactured by 
retailers and attract highly sensitive consumers' attention.

What kind of consumers would find most interested in this kind of discourse? This could be a kind of research question. According to recent research (Tachikawa et al. 2015), woman with high level of "cultural capital" (Bourdieu, 1984) shows tendency to have zero-tolerance attitude against food-related risk. Other variables, such as scientific literacy, educational level and trust, are controlled in a multi-regression model, but above mentioned group shows statistically significant differences in terms of propensity for zero-tolerance argument. This means that their cultural experience and knowledge seems to direct their opinion toward more stringent standard on food safely. Taking into consideration these women's role for leading opinion among their peers, science communication need to make an effort to deliver their voices to these very sensitive people.

\subsection{Diversification of food market channels}

Traditionally Japanese agricultural products have been distributed through JA (Japan agricultural cooperative) system (Ishizuka et al., 2016). This used to be true for many items, such as rice, fruit and vegetable. JA also have been depending on wholesale market for the outlet of their produce. In other words, agricultural distribution system has followed the Fordism model of production/consumption (Kawamura, 1991) which is characterized as large-scale, undifferentiated production. However, along with declining state control over farm product, in particular rice, the role of JA as distributor is declining and farmers or farm groups are trying to find their own distribution channel. In other words, traditional model is gradually being replaced by more consumer-oriented, differentiated distribution channel which is led by private retailers or farmers seeking for alternative channel. Farmers market, direct marketing, or teikei-type of relationships are being sought as alternatives.

Put in short, various issues mentioned above would demand us to tackle them not just from economic viewpoint but from other crucial viewpoints, such as social, political, environmental, welfare, transportation, and so on. Multi-facet nature of food problem calls for "food policy" in the sense of Tim Lang (2009) argues.

\subsection{Food Policy Council}

In this part, I would like to discuss an organization called as Food Policy Council (FPC). The number of FPC is rapidly increasing in North America in recent years (further details can be viewed at the website of the Johns Hopkins University). The 
number of the FPCs reaches more than 280 in the US and 60 in Canada in 2015. The increase is impressive especially after 2000 when urban food issues have been paid attention, such as food access and obesity. FPC can take various forms at the various levels; local, regional, and state. Some FPCs are well embedded in local government administration, while other FPCs are purely non-governmental entities.

Food policy council was initiated in the city of Knoxville, Tennessee US in 1982 (Petrey, 1990). This first FPC ever in the world was proposed by an urban planning researcher who had found that food issue is closely related to urban design/planning. Knoxville FPC has proposed many ideas to municipal government, such as change of bus route to cover grocery stores, revitalization of urban center to improve condition of food access, and so on. After Knoxville, many FPCs have been established in the North America. A FPC typically consists of 10-30 citizens who has various background related to food. The role of a FPC is usually playing a role for advisory for local government based on their discussion among various stakeholders (Harper et al., 2009). For example, Toronto FPC (TFPC) was established in 1991 under the City's Health Department as an advisory body (Blay-Palmer, 2009). Through the discussion of TFPC, various food related activities have been initiated and borne by various NPOs, such as food bank, new farmer program, roof top garden, urban agriculture, community garden, and so on. TFPC tends to provide a forum for various food related actors to discuss and provide recommendations to city government and stakeholders. Put in short, FPCs are playing an important role to generate ideas and facilitate actions to solve food problems (see Tables for further details).

As we have seen in the previous section, there are many kinds of food issues which need to be addressed by different stakeholders. One issue could also have in conflict with another, such as reduction of food loss and increasing food safety (Kobayashi, 2015). Therefore, it is difficult to find solution which meets every kind of request. Instead, we need to find most desirable and feasible solution within each local context. In this respect, it is crucial for all stakeholders to get together and deliberate possible options for their future activities. FPC could provide a forum for participants to discuss their roles and solutions. Until today food system issues have been left to private entities since it is designated as purely economic/profit making matter. I argue it is worth challenging this common sense today. Food system should be regarded as public issue, and FPC could provide the public forum to discuss it. 
Table 1. Example of Food Policy Council

\begin{tabular}{lcc}
\hline Name & Knoxvill-Knox County FPC & Toronto FPC \\
\hline Year & 1982 & 1991 \\
\hline $\begin{array}{l}\text { Number of } \\
\text { member }\end{array}$ & 11 (3-year term) & 30 (3-year term) \\
\hline Link with & Knox County Health Department & Toronto Board of Health
\end{tabular}

\begin{tabular}{|c|c|c|}
\hline Link with & Knox County Health Department & Toronto Board of Health \\
\hline Mission/Goal & $\begin{array}{l}\text { 1. Ensure that an adequate and nutritious food supply is } \\
\text { available to all citizens. } \\
\text { 2. Strengthen the economic vitality of the local food system. } \\
\text { 3. Improve the quality of food available to all citizens. } \\
\text { 4. Encourage citizens to accept and consume nutritious food. } \\
\text { 5. Minimize food-related activities which degrade the natural } \\
\text { environment; limit wasteful use of scarce resources needed for } \\
\text { future food production and distribution. }\end{array}$ & $\begin{array}{l}\text { 1. Advise and support Toronto Public Health in the development of } \\
\text { inclusive and comprehensive food security policies and programs } \\
\text { expressing internationally-recognized principles of healthy public policy, } \\
\text { social determinants of health, and the Ottawa Charter on Health } \\
\text { Promotion. } \\
\text { 2. Advocate for innovative community food security programs that } \\
\text { address City-wide commitments of the Toronto Food Strategy, Toronto } \\
\text { Food Charter and Toronto Environmental Plan. } \\
\text { 3. Foster dialogue with Toronto Public Health, community groups, social } \\
\text { agencies, educational institutions and businesses in the research, } \\
\text { promotion, design, implementation and evaluation of emerging ideas in } \\
\text { the field of community food security. } \\
\text { 4. Act as the community reference group for the Toronto Food Strategy } \\
\text { with a focus on identifying emerging issues, facilitating linkages between } \\
\text { the community, Toronto Public Health and City Divisions, and advising } \\
\text { the food strategy team on their implementation process. }\end{array}$ \\
\hline
\end{tabular}

\begin{tabular}{|c|c|c|}
\hline $\begin{array}{l}\text { Exar } \\
\text { activ } \\
\text { me }\end{array}$ & $\begin{array}{l}\text { - Expansion of KAT bus routes } \\
\text { - Expansion of school breakfast and lunch programs } \\
\text { - Support of the hen ordinance, which overturned the illegality } \\
\text { of hens within the City of Knoxville } \\
\text { - Encouragement of community gardening and local food } \\
\text { producing } \\
\text { - Establishment of the Calorie Conscious Consumer Project } \\
\text { - Establishment of a food monitoring system } \\
\text { - Hosting of community meetings which gave the council } \\
\text { information on what was important to the community } \\
\text { - Formation of a mapping Project with the Metropolitan } \\
\text { Planning } \\
\text { - Commission to examine locations of grocery stores and } \\
\text { farmland }\end{array}$ & $\begin{array}{l}\text { - Toronto Food Charter } \\
\text { - Greater Golden Horseshoe Alliance } \\
\text { - Toronto Food Strategy } \\
\text { - Healthy Cities, Healthy Public Policy } \\
\text { - Food Share } \\
\text { - Student Nutrition Programs } \\
\text { - Food Justice Day Proclamation } \\
\text { - Community kitchens } \\
\text { - Recreation Centre Soda Ban (not passed) } \\
\text { - Nutritious Food Basket } \\
\text { - Diabetes Prevention Strategy } \\
\text { - Food Advertising to Children } \\
\text { - Menu labeling } \\
\text { - Farmers Markets } \\
\text { - Community Gardens } \\
\text { - Urban Agriculture } \\
\text { - Urban Hens } \\
\text { - School Gardens }\end{array}$ \\
\hline
\end{tabular}

Source: Compiled by author based on the website of each FPC

As Ms. Dixie Petrey, first secretary of the Knoxville FPC, symbolically mentioned in her interview, like the case of water supply, food supply cannot be solved by individual action and it is the reason we need to cooperate as citizens. In this sense, citizens, rather than consumers, should be a main actor to realize improved food system in contemporary world (Renting et al., 2012). Rather than borrowing perspective from utility-maximizing consumer, food system issue should be discussed from public viewpoint of citizens to serve public good in certain context, I argue. In other words, we 
should consider multi-functionality of food. In the context of farm policy, we have been continuously discussing on multi-functionality of agriculture (OECD, 2001), such as flood control, groundwater recharge, idyllic landscape and so on. As we are seeing in our everyday life, food is playing an important role as medium for human interaction, city building (Roberts, 2014), education, tourism, and so on. Food is also worth attention to be seem from the viewpoint of multi-functionality.

One of the important point to study food is to focus on practice. As European researchers (Spaargaren, 2012) have been paying attention to importance of "practice," we need to take into account both structure and agency, and how both are interacting with each other and expressed as "practice." Practice is a focal point where intervention would be planned by policy-maker and social advocates. In the similar vein, FPC could focus on practice and may facilitate alternative practice to solve local problems and lessen environmental impact. In particular, the "structural" aspect of food system would be beyond individual control, and, therefore, it should be a target of public intervention. For example, urban planning (Pothukuchi and Kaufman, 2000) which takes into consideration food access issue could be desirable to solve food desert problem from a public point of view.

The demographic/geographical differences between North America and Japan have a profound impact on the structural aspect of food issue. Even if Japan could successfully introduce FPC model from the North America, still it is challenging how to tackle with urban food issues under such a super ageing society (Cabinet Office, 2016). Food issues for aged population are not well articulated in the context of North American FPC. Therefore, it would be left to our task how to tackle the issue. In addition, Japanese municipalities are locating very closely, and commercial/trading areas are penetrating one another. This locational condition of urban residents shows sharp contrast with North American situation. Taking into account this "structure" in urban area, it would be inappropriate to consider just one city/town covered by one FPC. Rather, Japanese people might need to seek a new model of FPC which covers multiple cities/towns.

\section{Conclusion}

As stated above, FPC's activities cover broad range of local food issues which are tackled by various stakeholders. Wide range of stakeholders are involved with FPC based on their expertise rather than representative of stakeholder's interest. I would argue that this kind of involvement of multi-stakeholders would constitute an ideal forum to address current complex issues of food system which Japanese society is now 
facing. However, in Japan, there is no such forum like FPC where citizens and stakeholders would meet with and discuss future solution of local food system to realize public good. Food system issues today need to be discussed as an important civic engagement. Citizens today tend to pay closer attention to various ethical issues, such as equity and sustainability (Lang, 2010). How we can find solutions in a local context and, at the same time, address these ethical, sometimes global, aspects in this kind of forum would be an open question.

\section{Acknowledgements}

This is a part of the research result supported by the FEAST Project organized by Steven McGreevy, the RIHN (Research Institute for Humanity and Nature) in Japan and the JSPS (Japanese Society for Promotion of Science) Grant coordinated by Professor Motoki Akitsu, Kyoto University (MEXT/JSPS KAKENHI Grant Number JP26292122).

\section{References}

Blay-Palmer, A., 2009. "The Canadian Pioneer: The Genesis of Urban Food Policy in Toronto", International Planning Studies 14(4): 401-416.

Bourdieu, P., 1984. Distinction: A Social Critique of the Judgement of Taste, Harvard University Press.

Cabinet Office, 2016. FY2016 White Paper on Aging Society. [Japanese]

Harper, A. et al., 2009. Food Policy Councils: Lessons Learned, Institute for Food and Development Policy, Institute for Food and Development Policy.

Ishizuka, S. et al., 2016. "The Current State of Marketing Strategies for Processing Vegetables: The Case of JA Aomori Vegetables Package Center," Bulletin of Tokyo Seiei College 8: 29-35.

Kawamura, Y., 1991. "Fundamental Issues for Rural Revitalization Associated with Regional Agriculture and Forestry," Journal of Rural Problem 105: 160-169 [Japanese].

Kobayashi, T. 2015. Shokuhin Loss no Keizaigaku (Economics of Food Loss), Norin-Tokei Shuppan. [Japanese]

Lang, T. et al., 2009. Food Policy: Integrating Health, Environment and Society, Oxford University Press.

Lang, T., 2010. "From 'value-for-money' to 'values-for-money'?: Ethical food and policy in Europe," Environment and Planning A 42: 1814-32. 
MAFF (Ministry of Agriculture, Forestry and Fisheries), 2006. Statistical Survey of Food Loss (Restaurant Industry Survey). [Japanese]

MAFF (Ministry of Agriculture, Forestry and Fisheries), 2016a. FY2015 Annual Report on Food, Agriculture and Rural Areas. [Japanese]

MAFF (Ministry of Agriculture, Forestry and Fisheries), 2016b. Reduction of Food Loss and Promotion of Recycle. [Japanese]

METI (Ministry of Economy, Trade and Industry), 2015. Manual for Supporting People with Poor Access to Food, ver3.0, [Japanese] (http://www.meti.go.jp/press/2015/04/20150415005/20150415005-4.pdf)

OECD, 2001. Multifunctionality: Towards an Analytical Framework.

Petrey, D.L., 1990. "Creating Health-Promotive Environments: Knoxville Food Policy Council Case Study" A. Evers, et al. eds. Healthy Public Policy at the Local Level. Westview Press, pp. 67-81.

Pothukuchi, K. and Kaufman, J.L., 2000. "The Food System: A Stranger to the Planning Field" Journal of American Planning Association, 66(2): 113-124.

Renting, H. et al., 2012. "Building Food Democracy: Exploring Civic Food Networks and Newly Emerging Forms of Food Citizenship," International Journal of Sociology of Agriculture and Food 19 (3).

Roberts W., 2014. Food for City Building: A Field Guide for Planners, Actionists and Entrepreneurs, Hypenotic Inc.

Sonnino, R. and Spayde, J. J., 2014. "The New Frontier? Urban Strategies for Food Security and Sustainability" T. Marsden and A. Morley eds. Sustainable Food Systems: Building a New Paradigm. Routledge, pp.186-205.

Spaargaren, G. et al., 2012. Food Practices in Transition, Routledge.

Tachikawa, M., Kato, N. and Matsuo, M., 2015. Factors affecting zero-tolerance attitude among consumers: Implications from Cultural Capital. Journal of Food System Research 22(3): 271-276. [Japanese]

Toronto Food Policy Council, 2012. An Urban Agriculture Action Plan for Toronto.

Toronto Food Policy Council, 2015. Toronto Food Policy Archive: Food Policy Decisions in Toronto.

Uneyama, C., 2011, Anzen na Tabemono tte Nandaro (What is "safe" Food?), Nihon-Hyoronsya. [Japanese]

Yakushiji, T. (ed.), 2015. Difficulties in Accessing Grocery Stores in a Super-Aged Society, Harvest-sha. [Japanese] 